\title{
Evaluation of Shot Peening on the Fatigue Strength of Anodized Ti-6Al-4V Alloy
}

\author{
Midori Yoshikawa Pitanga Costa ${ }^{\mathrm{a} *}$, Herman Jacobus Cornelis Voorwald, \\ Walter Luis Pigatin ${ }^{\mathrm{b}}$, Valdir Alves Guimarães ${ }^{\mathrm{a}}$, Maria Odila Hilário Cioffic \\ ${ }^{a}$ Fatigue and aeronautical materials research group, \\ Department of Materials and Technology, State University of São Paulo, \\ Av. Ariberto Pereira da Cunha, 333, 12516-410 Guaratinguetá - SP, Brazil \\ ${ }^{\mathrm{b}}$ Embraer Liebherr Equipamentos do Brasil Ltda., \\ Rua Itabaiana, 40, 12237-540 São José dos Campos - SP, Brazil \\ 'IPOLI - UNESP/Sorocaba, Av. 3 de março, 511, 18087-180 Sorocaba - SP, Brazil
}

Received: December 2, 2004; Revised: January 2, 2006

\begin{abstract}
The increasingly design requirements for modern engineering applications resulted in the development of new materials with improved mechanical properties. Low density, combined with excellent weight/strength ratio as well as corrosion resistance, make the titanium attractive for application in landing gears. Fatigue control is a fundamental parameter to be considered in the development of mechanical components. The aim of this research is to analyze the fatigue behavior of anodized Ti-6Al-4V alloy and the influence of shot peening pre treatment on the experimental data. Axial fatigue tests $(R=0.1)$ were performed, and a significant reduction in the fatigue strength of anodized Ti-6Al-4V was observed. The shot peening superficial treatment, which objective is to create a compressive residual stress field in the surface layers, showed efficiency to increase the fatigue life of anodized material. Experimental data were represented by S-N curves. Scanning electron microscopy technique (SEM) was used to observe crack origin sites.
\end{abstract}

Keywords: fatigue, anodization, titanium, shot peening

\section{Introduction}

Considering the surface-environment interactions to which some components of the aircraft industry are exposed, the study of protection against wear and corrosion induced by the use of coatings is an important research field in aeronautical engineering ${ }^{1}$. Chromium plating is the most used electroplated coating to obtain high level of hardness, wear and corrosion resistance, and low coefficient of friction. However, problems such as health and environmental hazards, resulted in a search for possible alternatives to hard chrome plating ${ }^{2-4}$. Tungsten carbide (WC) thermal spray coating applied by the high velocity oxy-fuel process (HVOF) is been considered an alternative candidate to fulfill project requirements ${ }^{5}$.

Titanium and titanium alloys are excellent candidates for aerospace applications. Ti-6Al-4V is the workhorse of titanium industry, accounting for more than $50 \%$ of all titanium tonnage in the world. This alloy has a yield strength of $868 \mathrm{MPa}$, good fatigue properties and moderate fracture toughness. Mechanical properties combinations for titanium alloys can be significantly changed through processing as well as by heat treatment variation ${ }^{6,7}$. It's well known that Ti-6Al-4V has an excellent corrosion resistance with the added benefit of reduced weight; on the other hand surface protection is necessary to avoid the corrosion-fatigue mechanism and its reactivity towards atmospheric oxygen. To overcome these limitations, anodization is an electrochemical process used to obtain a protective oxide film on the metallic job, which reduce the friction on sliding surfaces and protect the metal from atmospheric corrosion ${ }^{8}$.

Fatigue control is a major consideration in the development of a new material for aircraft industry, mainly when components are subjected to constant and variable amplitude loading ${ }^{9,10}$. Whereas surface treatments, like anodic coatings, usually degrade the fatigue life performance of a material, a mechanical surface treatment may be responsable for an increase in the fatigue strength ${ }^{11}$.

An effective method of improving the fatigue strength of metal components is shot peening, which consists in impacting a surface by a flow of spheroidal shots with a kinetic energy sufficient to cause plastic strain of the sub-surface layer of the material and, consequently, to induce a compressive residual stress field ${ }^{12,13}$.

In general, fatigue crack initiation occurs on the specimen surface. Wang et al. ${ }^{14}$ demonstrated that fatigue crack can be initiated from the interior of many materials in the case of high cycle fatigue. Shengping Wang et al. ${ }^{15}$ showed that the shot peening process pushes the crack initiation points beneath the compressive residual stress zone.

Subsurface fatigue crack nucleation, in mechanically surface treated specimens, as a result of residual tensile stress balancing the other beneficial compressive stress field is normally observed ${ }^{16}$.

The objective of this paper is to analyze the effect of anodizing on the axial fatigue strength of Ti-6Al-4V alloy. The influence of compressive residual stress field induzed by the shot peening process on the fatigue data of anodized substrate, was also identified.

\section{Experimental Procedures}

The chemical composition of Ti-6Al-4V used was $6.13 \% \mathrm{Al}$, $4.0 \% \mathrm{~V}, 0.23 \% \mathrm{Fe}, 0.19 \% \mathrm{O}, 0.07 \% \mathrm{Ni}, 0.0124 \% \mathrm{H}, 0.004 \% \mathrm{Y}$, $0.39 \%$ residual elements, Ti reminder. Mechanical properties of this alloy are: (35-40) HRc and ultimate strength of $1270 \mathrm{MPa}$, in the annealed condition.

Axial fatigue tests according to ASTM 466 were conducted using a sinusoidal load of frequency $20 \mathrm{~Hz}$ and ratio $\mathrm{R}=0.1$, at room 
temperature considering, as fatigue strength, the complete specimens fracture or $10^{7}$ load cycles. Three groups of fatigue specimens, showed in Figure 1, were prepared to obtain S-N curves for axial fatigue tests:

- Specimens of base metal;

- Specimens of base metal anodized; and

- Specimens of base metal shot peened and anodized.

Anodization of the titanium was performed in an electrolyte on the base of sulfuric acid at a voltage of $20 \mathrm{~V}$ for 15 minutes. The coating thickness shall be: $2.50 \pm 1.27 \mu \mathrm{m}$, according to MIL-A-24641.

The shot peening parameters were: intensity of $0.008 \mathrm{~A}$, out flow of $3 \mathrm{Kg}$, a speed of $250 \mathrm{~mm} / \mathrm{min}$, a distance $200 \mathrm{~mm}$ and rotation $30 \mathrm{rpm}$. The steel shot used was $\mathrm{S} 230(\varnothing 0.7 \mathrm{~mm})$. The process was carried out on an air-blast machine according to standard SAEAMS-S-13165.

The fracture planes of the fatigue specimens were examined using a scanning electron microscopy model Zeiss DSM 950 in order to identify the crack initiation points.

\section{Results and Discussion}

The extend to which anodic coatings can reduce the fatigue strength of Ti-6Al-4V alloy, is illustrated in Figure 2.

The fatigue life in the shot-peened/anodized Ti-6Al-4V alloy is improved by around two orders of magnitude, in comparison with the anodized condition, while the increase in fatigue strength indicates that the detrimental effects of the anodic coating is counterbalanced by the compressive residual stresses induced by the shot peening.

For $\sigma_{\max }$ equal to $985 \mathrm{MPa}$, average number of cycles to failure for Ti-6Al-4V, anodized Ti-6Al-4V and shot-peened/anodized Ti-6Al-4V are: 143300,15048 and 33089, respectively. These results indicate a severe decrease in fatigue strength for the anodized conditions and a slightly improvement due to the shot peening process. Number of cycles to failure for the anodized condition was around $10.5 \%$ of the base metal fatigue life and $220 \%$ increase due to the shot peening process occurred.

At stress level $955 \mathrm{MPa}$, average fatigue life for base metal, anodized base metal and shot peened/anodized base metal was 526460 cycles, 52550 cycles and 129850 cycles, respectively. Approximately the same decrease in number of cycles to failure and increase caused by the shot peening was observed, $10 \%$ and $247 \%$, respectively.

Figure 3 shows a typical fracture surface from the base metal, indicating that the fatigue crack nucleation started at the surface.

In Figure 4, several crack fronts that may be associated to the anodic coating, are represented and responsible for the decrease in fatigue life.

From Figure 5, which represents fracture surface from an axial fatigue specimen shot peened/anodized Ti-6Al-4V, one sees that the shot peening process increased the substrate strength and delayed fatigue crack propagation through base metal.

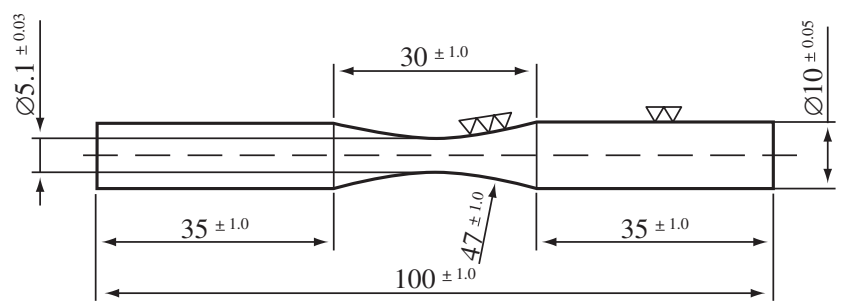

Figure 1. Axial fatigue testing specimen.

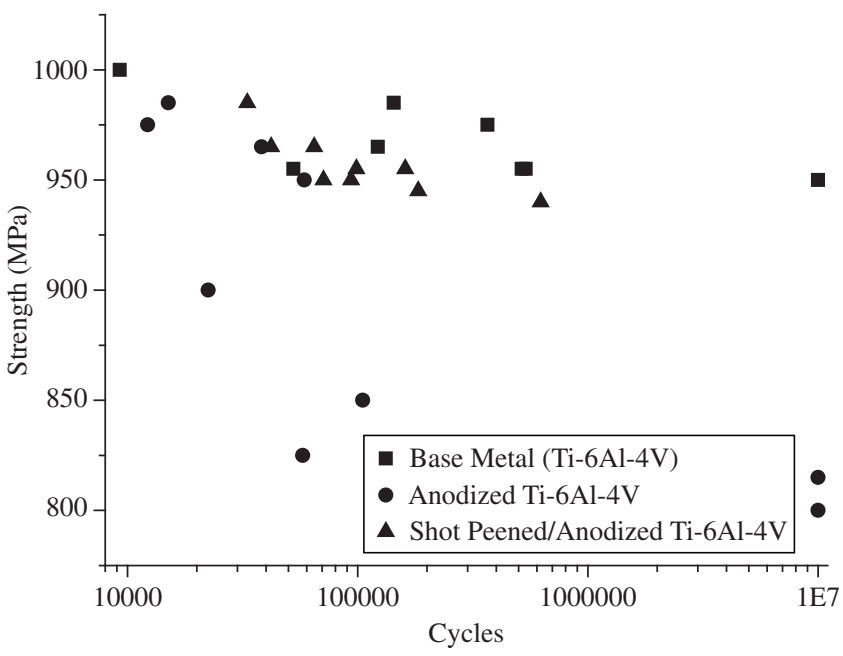

Figure 2. S-N Curves $(\mathrm{R}=0.1)$.

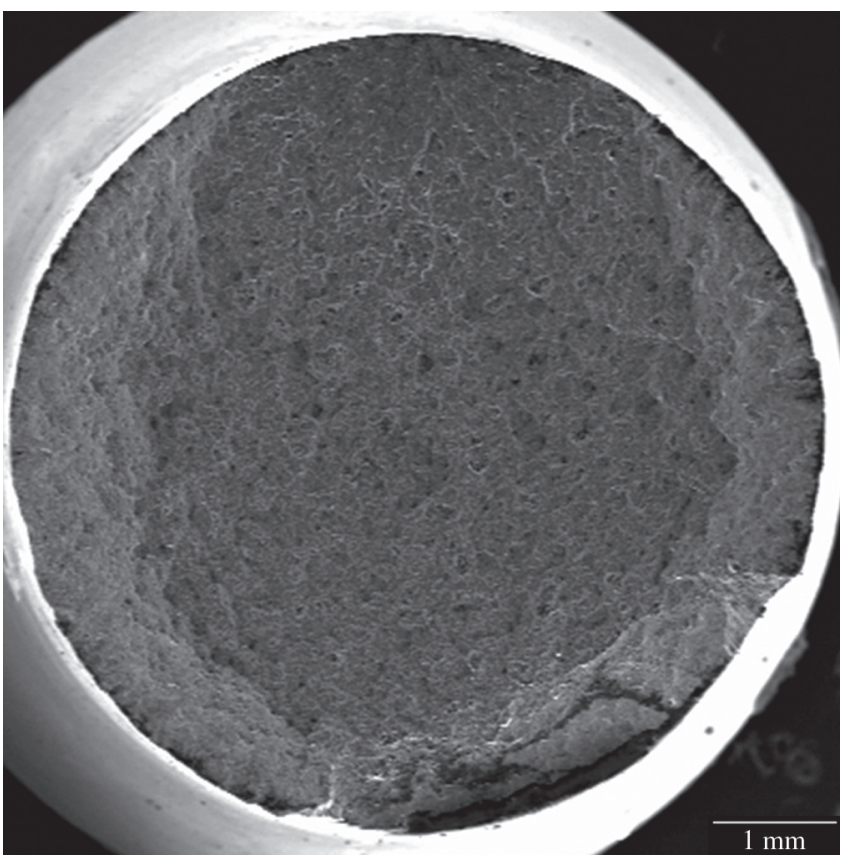

Figure 3. Typical fracture surface from base metal.

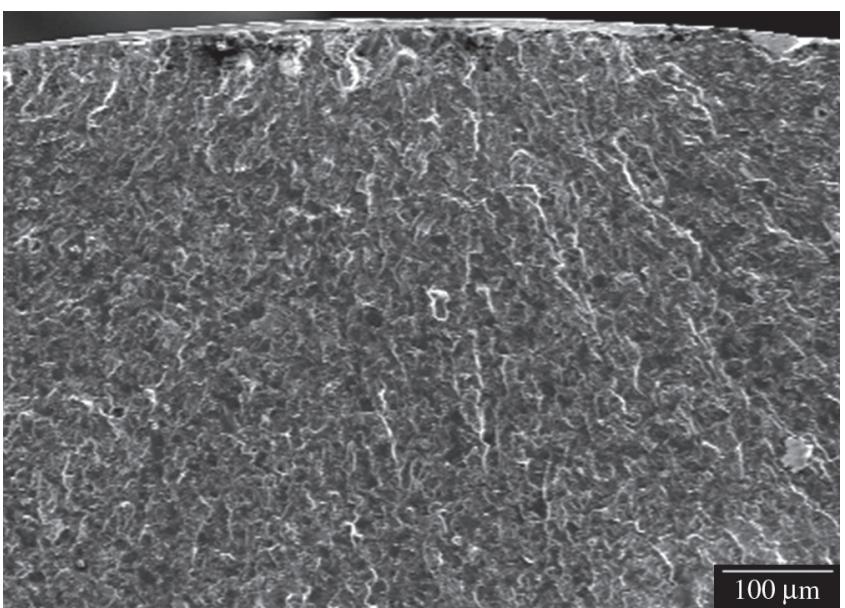

Figure 4. Fracture surface from the anodized Ti-6Al-4V $\left(\sigma_{\text {max. }}=900 \mathrm{MPa}\right)$. 


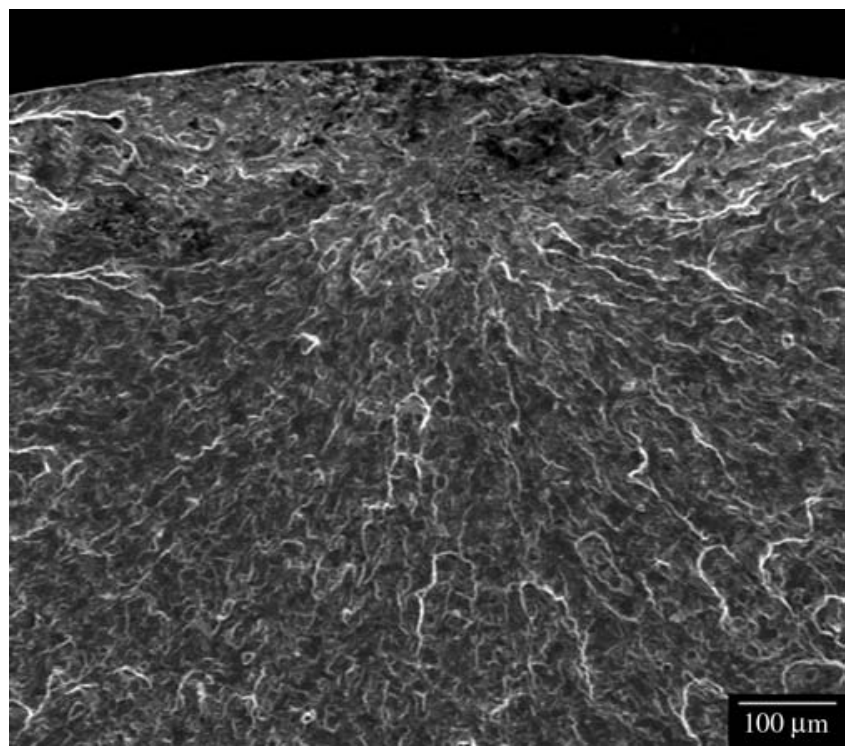

Figure 5. Fracture surface from the shot peened anodized Ti-6Al-4V $\left(\sigma_{\max .}=940 \mathrm{MPa}\right)$.

\section{Conclusion}

- The extend to which anodic coatings can reduce the fatigue strength of Ti-6Al-4V alloy, is illustrated in Figure 2. The effect of anodic coatings was to decrease the fatigue strength for Ti-6Al-4V alloy;

- At stress levels $986 \mathrm{MPa}$ and $955 \mathrm{MPa}$, reduction in number of cycles to failure due to the anodic coatings, and increase in fatigue life after shot peening process were, respectively, $10.50 \% / 219.9 \%$ and $9.98 \% / 247.1 \%$; and

- Shot peening pre-treatment proved to be an efficient process to improve the fatigue strength of anodized Ti-6Al-4V base metal.

\section{Acknowledgments}

The research was supported by ELEB (Embraer-Liebherr).

\section{References}

1. Souza RC, Nascimento MP, Voorwald HJC, Pigatin WL. The effect of WC-17Co thermal spray coating by HVOF and hard chromium electro- plating on the fatigue life and abrasive wear resistance of AISI 4340 high strength steel. Journal of Mechanical Behavior. 2001; 12(3):121-140.

2. Nascimento MP, Souza RC, Miguel IM, Pigatin WL, Voorwald HJC. Effects of tungsten carbide thermal spray coating by HP/HVOF and hard chromium electroplating on AISI 4340 high strength steel. Surface \& Coatings Technology. 2001; 138(2-3):113-124.

3. Nascimento MP, Voorwald HJC, Souza RC, Pigatin WL. Evaluation of an electroless nickel interlayer on the fatigue and corrosion strength of chromium-plated AISI 4340 steel. Plating \& Surface Finishing. 2001; 88(4):84-90.

4. Ko PL, Robertson MF. Wear characteristics of electrolytic hard chrome and thermal sprayed $\mathrm{WC}-10 \mathrm{Co}-4 \mathrm{Cr}$ coatings sliding against Al-Ni-bronze in air at 21 degrees $\mathrm{C}$ and at-40 degrees C. Wear. 2002; 252(11-13):880-893.

5. Bogder BE, McGrann RTR, Somerville DA. The evaluation of tungsten carbide thermal spray coatings as replacements for electrodeposited chrome plating on aircraft landing gear. Plating Surface Finishing. 1997; 84(9):28-31.

6. Boyer RR. An overview on the use of titanium in the aerospace industry. Materials Science \& Engineering A. 1996; 213(1-2):103-114.

7. Boyer R, Welsch G, Collings EW. Materials properties handbook: titanium alloys. Materials Park, OH: ASM International, 1994.

8. Sharma AK. Anodizing titanium for space applications. Thin Solid Films. 1992; 208(1):48-54.

9. Barter SA, Clayton JQ, Clark G. Aspects of fatigue affecting the design and maintenance of modern military aircraft. International Journal of Fatigue. 1993; 15(4):325-332.

10. Torres MAS, Voorwald HJC. An evaluation of shot peening, residual stress and stress relaxation on the fatigue life of AISI 4340 steel. International Journal of Fatigue. 2002; 24(8):877-886.

11. Eifert AJ, Thomas JP. Influence of anodization on the fatigue life of WE43A-T6 Magnesium. Scripta Materialia. 1999; 40(8):929-935.

12. Guagliano M, Vergani L. An approach for prediction of fatigue strength of shot peened components. Engineering Fracture Mechanics. 2004; 71(4-6):501-512.

13. Wang S, Li Y, Yao M, Wang R. Compressive residual stress introduced by shot peening. Journal of Materials Processing Technology. 1998; 73(1-3):64-67.

14. Wang QY, Baudry G, Bathias C, Berard JY. Subsurface crack initiation due to ultra-high cycle fatigue. In: Advances in Mechanical Behavior, Plasticity and Damage, Proceedings of EUROMAT; 2000; AmsterdamLausanne. New York, Elsevier. 2000; 2:1083-1087.

15. Wang S, Li Y, Yao M, Wang R. Fatigue limits of shot peened metals. Journal of Materials Processing Technology. 1998; 73(1-3):57-63.

16. Wagner L. Mechanical surface treatments on Titanium, Aluminum and Magnesium Alloys. Materials Science and Engineering A. 1999; 263(2):210-216. 